\title{
Nucleic Acids, Nucleosides, and Nucleotides
}

National Cancer Institute

\section{Source}

National Cancer Institute. Nucleic Acids, Nucleosides, and Nucleotides. NCI Thesaurus.

Code C708.

A header concept for chemicals that are the building blocks of inherited genetic

information. The monomer structure (nucleoside) contains either a purine or pyrimidine base linked to a deoxyribose or ribose carbohydrate group. Nucleotides are composed of a nucleoside and one to three phosphate groups. Nucleic acids are polymers of nucleotides that are linked by phosphodiester bonds. 